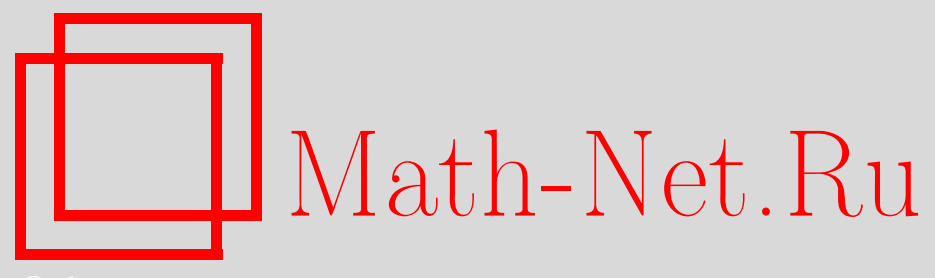

Г. Горелик, Симметрии в несимметричной вселенной Андрея Сахарова, Квант, 2019, номер 7, 2-9

DOI: https://doi.org/10.4213/kvant20190701

Использование Общероссийского математического портала Math-Net.Ru подразумевает, что вы прочитали и согласны с пользовательским соглашением http://www.mathnet.ru/rus/agreement

Параметры загрузки:

IP : 54.237 .59 .107

26 апреля 2023 г., 18:16:21

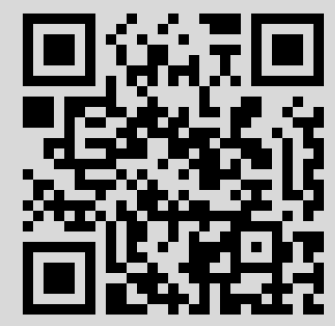




\section{Симметрии в несимметричной вселенной Андрея Сахарова}

\section{Г.ГОРЕЛИК}

\section{Биографы седьмого класса}

На мое желание заняться биографией Андрея Дмитриевича Сахарова откликнулся заокеанский Институт истории науки и техники. Вот почему в 1993 году я с семьей оказался в небольшом американском городе Бруклайне, что входит в Большой Бостон. Спустя три года я попал в кабинет директора Бруклайнской школы. Дело в том, что к тому времени мой сын настолько освоился в школе, что на перемене подрался с одноклассником.

Разбирательство директор школы проводил на моих глазах. И делал это замечательно. С уважением к достоинству 13-летних граждан он сообщил им немногословно, негромко, но совершенно твердо, что еще один подобный случай станет их последним событием в этой школе. После разбирательства, отпустив правонарушителей, директор вдруг спросил меня, не могу ли я рассказать семиклассникам о своих биографических исследованиях. Эта идея, думаю, неслучайно посетила директора школы, как-то узнавшего, что родитель его семиклассника пишет книгу о знаменитом гуманитарном физике. Биографией в этой школе занимались всерьез. Каждому семикласснику предоставили выбрать, по своему вкусу, личность, чем-нибудь замечательную, - хоть Архимеда, хоть кинозвезду. Надо было, собрав в библиотеке сведения, написать биографию, подобрать иллюстрации и, наконец, на итоговом смотре в школьном зале перевоплотиться в избранную замечательную личность. Вместе с другими родителями я побывал на этом перевоп-

DOI: https://doi.org/10.4213/kvant20190701

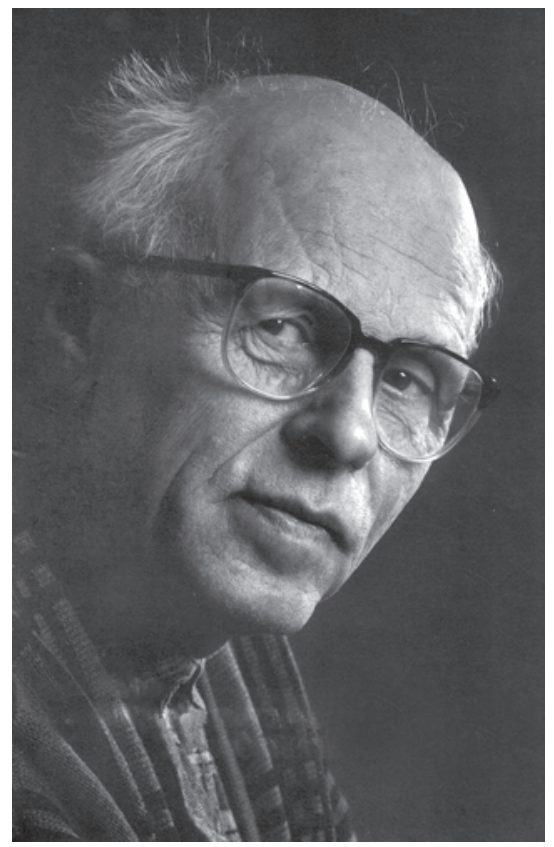

Андрей Дмитриевич Сахаров

лощении. Побеседовал там с Эйнштейном, Пикассо, с каким-то знаменитым (хоть и неизвестным мне) футболистом. Другие родители беседовали с моим сыном, перевоплотившимся в Леонардо да Винчи, и он им объяснял свою Джоконду и свои научные изобретения.

Получив нежданное домашнее задание, я начал думать, как рассказать американскому семикласснику о человеке, который в далекой советской России изобретал водородную бомбу, разгадывал загадки Вселенной, защищал свободу мысли и отстаивал права человека. Задание нелегкое.

Несколько недель спустя, в том же самом школьном зале, где происходили био- 
графические перевоплощения, те же самые семиклассники уютно расселись прямо на полу и устремили свои пытливые глаза на пришельца. Накануне каждый из них получил по листочку, в котором его спросили, знает ли он:

- что во время второй мировой войны советские и американские солдаты воевали с общим врагом - нацизмом;

- но что спустя полтора десятилетия советские термоядерные ракеты были нацелены на американские города, а американские ракеты - на Россию;

- что советское термоядерное оружие придумал молодой физик Андрей Сахаров и за это был щедро награжден советским правительством;

- что, осознав зловредное воздействие атмосферных ядерных испытаний на здоровье человечества, он способствовал запрету таких испытаний;

- а поняв, что несвобода угрожает жизни человечества, начал отстаивать права человека как основу надежного мира между народами;

- что его усилия Нобелевский комитет наградил премией мира, а советское правительство - высылкой в город Горький;

- что физика Сахарова больше всего интересовало, как устроена Вселенная;

- и - семиклассникам на десерт - что Андрей Сахаров начал учиться в школе именно с седьмого класса, а до того учился дома.

\section{Из рукописного наследия Андрея Сахарова}

Лучше один раз увидеть, чем сто раз услышать, и, чтобы помочь 13-летним американцам понять русского физика-гуманиста, я захватил с собой две его маленькие рукописи. Я надеялся, что они помогут связать невероятные повороты Сахаровской биографии, показав, как могут быть связаны симметрия и асимметрия.

Первой я показал рукопись, написанную частично на интернациональном языке арифметики (рис.1). Как только картинка появилась на экране, темнокожая отличница из первого ряда деликатно подсказала мне, что «прозрачку» я положил

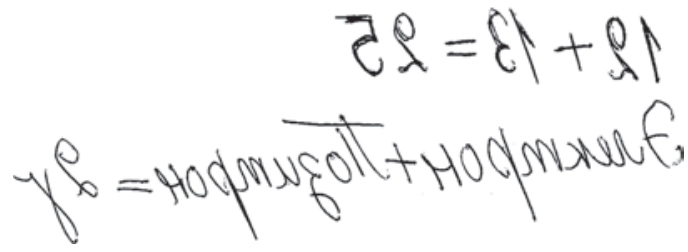

Pис. 1

не той стороной. (В те времена еще не научились показывать картинки прямо из флэшки, да и флэшку еще не изобрели. Поэтому приходилось печатать-писать-рисовать на прозрачных листах, которые помещали в проектор, иногда не той стороной.) Тогда я предъявил второй автограф, уже без арифметики (рис.2), и объяснил, что Сахаров умел писать не

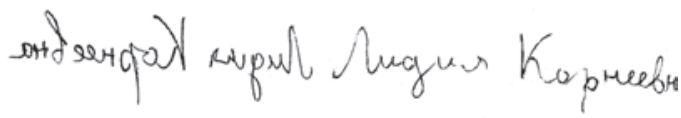

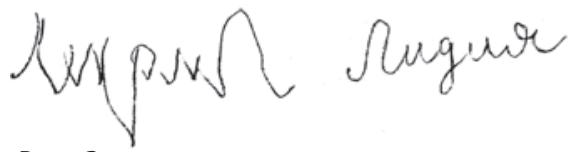

Puc. 2

только одной рукой в зеркальном изображении, но и обеими руками одновременно в разные стороны. А Лидия Корнеевна Чуковская, которой он демонстрировал свое умение и которая сберегла эти автографы, очевидно, так не умела. Если бы она была право-лево-рукой, как Сахаров, и если бы они оба писали поанглийски, то мои слушатели увидели бы нечто, похожее на бабочку (рис.3). Труднее было объяснить по-английски, как

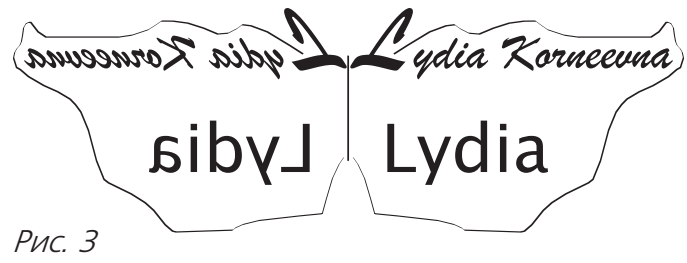

защита униженных и оскорбленных связала этих двух людей с разными жизненными призваниями: у одного - физика, у другой - лирика. А что они не замыкались в своих мирах, ясно из приведенных картинок. 
Эти же картинки помогли мне рассказать семиклассникам о симметриях и несимметриях того мира, в котором Андрею Сахарову довелось жить. Вот этот рассказ.

\section{Правое и левое}

В первые американские месяцы меня поразило обилие людей, пишущих левой рукой. За сорок пять лет предыдущей российской - жизни ничего подобного я не видел. Разумеется, я знал, что такие люди есть, и конечно же читал лесковского «Левшу», но почему-то в повседневной жизни их не встречал и даже как-то связывал печальную судьбу Левши с его врожденной особенностью.

Сахарову повезло, что он относился к еще более редкому меньшинству обоюдоруких и потому был не столь уязвим для подавляющего большинства праворуких. Но что если бы его родители не обеспечили ему домашнее образование до 7-го класса, а сразу отдали бы его на перевоспитание в советскую школу? А там - по Маяковскому - скомандовали бы: «Кто там пишет левой?! Правой! Правой! Правой!» По мнению самого Андрея Сахарова, долгое домашнее обучение усилило его «неконтактность, от которой [он] страдал потом и в школе, и в университете, да и вообще почти всю жизнь». Кто знает, ранние тесные контакты с советской жизнью могли бы и подорвать чувство собственного достоинства этого мягкого человека с твердыми моральными устоями, и лишить его способности быть в меньшинстве. А ведь в науке новое слово всегда говорит самое маленькое меньшинство - один человек.

\section{Симметрии в физике и политике}

Словом «симметрия» обычно описывают форму здания, узор, геометрическую фигуру - это всегда какая-то закономерность формы. Однако в 20-м веке удалось в физических законах разглядеть проявления симметрий мироздания. Выяснилось, например, что крутящийся волчок долго не падает просто потому, что «не знает», в какую сторону упасть: все горизонтальные направления в пространстве равноправны
- все стороны симметричны относительно вертикальной оси. ${ }^{1}$ И вообще, всякий фундаментальный физический закон раскрывает некую симметрию Вселенной. Если же эксперимент обнаруживает какую-то асимметрию, то физик-теоретик получает трудную, но захватывающе интересную задачу - найти место этой асимметрии в гармонии мироздания.

Подобной задачей Сахаров заинтересовался в 60-е годы. Симметрия бабочки, или зеркальная симметрия, причастна к самой значительной его идее в космологии - в физике Вселенной. Однако прежде чем заняться этой абсолютно мирной идеей, предыдущие два десятилетия своей жизни - наиболее плодотворные годы для физика-теоретика - Сахаров отдал созданию самого разрушительного оружия в истории человечества. Почему? Асимметрии, формировавшие его жизнь, относилась не к физике, а к политике.

Андрей Сахаров поступил в университет в 1938 году, накануне мировой войны. Мир тогда представлялся ему крайне асимметричным. Впереди планеты всей шла страна, в которой ему посчастливилось родиться. Шла навстречу светлому будущему, обществу всепланетной социальной справедливости и беспредельных возможностей. Позади оставались страны капитализма и среди них наиболее зловещая гитлеровская Германия, в которой надругались над словом «социализм» приставкой «национал-» и отвергали научные теории изза их «неарийского» происхождения.

Асимметрию эту отменила мировая война. Заостренная ось Берлин-Токио вонзилась почти одновременно в коммунистическую диктатуру и в крупнейшую капиталистическую демократию, что породило странную симметрию под немыслимым прежде названием «Объединенные нации» ,

1 Знаменитая теорема Нётер (доказанная Эмми Нётер в 1918 году) связывает различные симметрии физических систем с законами сохранения. В частности, изотропность пространства (равноправие всех направлений) связана c законом сохранения момента импульса. (Прим. ред.) 
когда США и Великобритания стали союзниками СССР в войне против нацистской Германии.

Четыре года спустя, сломав воинственную ось, победившие союзники создали международную организацию - Организацию Объединенных нации - в качестве инструмента поддержания мира. После исчезновения оси, однако, «осевая» симметрия стремительно преобразилась в антисимметрию, и первые ядерные взрывы обозначили это превращение. В Хиросиме и Нагасаки наука зримо вошла в политику. И физики, причастные к этому, быстрее политиков поняли, что новая антисимметрия чревата самоуничтожением человечества. Крупнейшие физики-теоретики 20-го века Эйнштейн и Бор обращались к новорожденному мировому парламенту ООН, призывая создать мировое правительство, чтобы ядерный век не стал последним веком цивилизации. Увы, тогда это была слишком теоретическая идея.

\section{Теоретик-изобретатель}

Слишком теоретической для 20-летнего Андрея Сахарова была и обрисованная глобальная картина мировых симметрий. В зловеще-практических обстоятельствах, когда фашисты подошли к Москве, студент-четверокурсник эвакуировался вместе с университетом в далекий Ашхабад. И после ускоренного окончания университета отправился на военный завод в Ульяновске. Завод делал патроны - для фронта, для победы. А молодой специалист по «оборонному металловедению», стараясь помочь победе, изобрел магнитный прибор для проверки качества пуль. И первая его самостоятельная задача в теоретической физике родилась из размышлений над этим изобретением.

Чтобы из патронного производства возникла физическая задачка сомнительной важности, нужен человек с призванием физика-теоретика. Иначе изобретение вполне конкретного прибора не поведет к странному вопросу: а что если магнитные силы заменить электрическими? Это был не производственный вопрос, это был вопрос к природе, в которой имеется стран- ная симметрия электричества и магнетизма.

За сорок лет до того служащий патентного бюро в Берне Альберт Эйнштейн, размышляя над кажущейся несимметрией движущихся зарядов, создал самую знаменитую физическую теорию - теорию относительности. Начиная размышлять о какой-нибудь несимметрии природы, теоретик не знает, придет ли он к новой теории, просто к новой формуле или не придет ни к чему разумному вовсе. Но движет размышлениями одно и то же стремление к познанию.

Итак, в самом теплом и светлом помещении У льяновского патронного завода - в парткабинете, рядом с полками политических книг, молодой инженер занимался теоретической физикой и придумал-таки, как решить свою электромагнитную задачу. За этой задачей последовали другие ненужные для патронного производства, но интересные для начинающего теоретика. Теоретик задавал Природе вопросы, ответы на которые получал с помощью физических рассуждений и математики, умело распоряжаясь симметриями и асимметриями. Только одну из этих задач можно понять без пояснений: «С какой скоростью увеличивается толщина льда, окруженного ледяной водой?»

Решения двух других задач начинающий теоретик отправил отцу в Москву, а тот показал их Игорю Евгеньевичу Тамму, главному теоретику в Физическом институте Академии наук. В результате в начале 1945 года Андрей Сахаров стал аспирантом ФИАНа и целиком отдался теоретической физике. На чистую науку история дала ему всего несколько лет. Атомный взрыв в Хиросиме в августе 1945 года был услышан и в Советском Союзе. Ядерная асимметрия требовала ответа. Так считали не только политики, но и российские физики. Восстановление симметрии, создание советского ядерного оружия для физиков было не столько великодержавной претензией, сколько предотвращением новой войны. Летом 1948 года к разработке супер-бомбы подключили И.Е.Тамма и его сотрудников. Сахаров, только что за- 


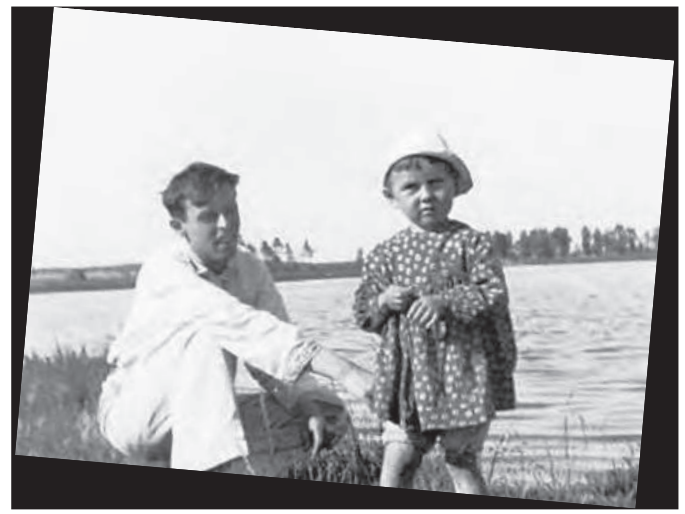

Андрей Сахаров с дочкой, лето 1948 года (несимметрично нацеленный фотоаппарат)

щитивший диссертацию по чистой науке, вернулся к физико-техническому изобретательству. Почти на два десятилетия. Он считал это дело необходимым, оно ему нравилось, и оно у него получалось. Через считанные недели у Сахарова родится идея «Слойки» - первой советской термоядерной бомбы. «Это лето памятно мне блеском воды, солнцем, свежей зеленью, скользящими по водохранилищу яхтами ... Несмотря на летнее время, мы все работали очень напряженно. Тот мир, в который мы погрузились, был странно-фантастическим, разительно контрастировавшим с повседневной городской и семейной жизнью за пределами нашей рабочей комнаты, с обычной научной работой».

Изобретательство совместимо с теоретической физикой. Знаменитый теоретик Энрико Ферми об изобретатении супербомбы сказал: «Превосходная физика!» Ведь термоядерный взрыв с его астрономическими температурами и давлениями дает теоретику возможность «проникнуть» внутрь звезды.

Bсе это так. Но спустя сорок лет Сахаров с грустью писал в письме: «Пытаюсь изучать сделанное умными людьми в области квантовой теории поля ... вещь крайне трудная, и я часто отчаиваюсь когда-нибудь выйти на должный уровень - упущено с 1948 года слишком многое, сплошные пробелы, и все последующие годы я только за счет удачи и «нахальства» мог что-то делать, часто попадая впросак или работая впустую». «Нахальство» по-другому называется смелостью, а удача - награда за смелость и в науке. Но нет оснований не верить Сахарову: термоядерное изобретательство отняло слишком много его сил.

\section{Изобретательный теоретик или практический политик?}

Как ни увлекательно видеть в водородной бомбе искусственную звезду, к концу 50-х годов цель была достигнута, научно проблема исчерпалась. Настала очередь изощренной техники. Там тоже есть творческий простор, но не для физика-теоретика. А как быть теоретику, который знает, что изобрел самое могущественное оружие в истории и - по воле истории - стал очень влиятельным ученым в военно-научном комплексе страны? Ответственность за происходящее вокруг - родовое чувство российской интеллигенции - привело физика-теоретика в практическую политику.

Свою политическую биографию Сахаров начал в области своей профессии: его заботили ядерные испытания в атмосфере - вредоносные для человечества и необязательные для поддержания ядерного баланса. Начинающему политику сопутствовал успех - в 1963 году международный договор запретил надземные испытания. Это утвердило Сахарова в важности своей новой роли. Вместе с тем, общение с высшими руководителями государства давало ему опытные знания о советском правительстве, недоступные другим. Сама проблема стратегического равновесия связана с общим потенциалом государства и общества.

В середине 60-х годов развитие ядерноракетного оружия подвело к необычайно опасному повороту в гонке вооружения, хотя речь шла об обороне. Противоракетная оборона оказалась опаснее для мира, чем средства нападения. Этот неочевидный, но вполне вероятный вывод Сахаров, как один из высших военно-технических экспертов, попытался объяснить правительству 21 июля 1967 года. Он направил - секретной почтой - соответ- 
ствующее разъяснение. Однако советские руководители отвергли, а точнее проигнорировали, это предостережение.

Полученные «экспериментальные» факты о советском режиме и о состоянии ядерноракетного противостояния требовали теоретического осмысления, результатом чего и стали Сахаровские «Размышления о прогрессе, мирном сосуществовании и интеллектуальной свободе». В мае 1968 года он выпустил свою статью в Самиздат, в июле перевод статьи опубликовали на Западе. Сахаров не проповедовал мораль несимметричному человечеству, а предложил конкретный путь к симметризации - он был не

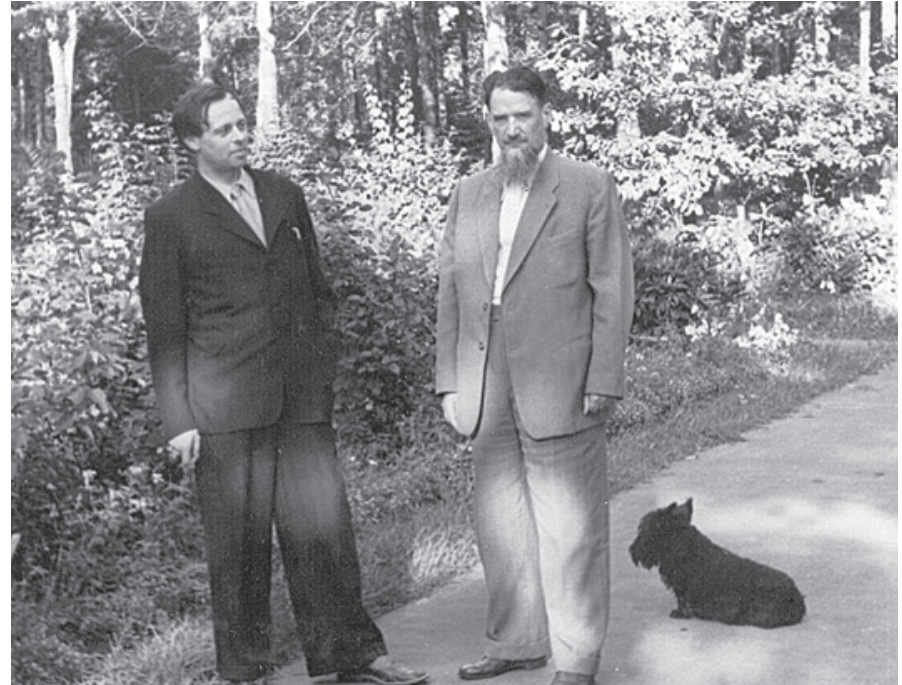

Дважды Герой Социалистического Труда академик Андрей Сахаров и трижды Герой Социалистического Труда академик Игорь Курчатов, 1958 год морализатор, а теоретик-изобретатель. Корневая проблема выросла из его профессиональной области: как человечеству выжить в условиях ядерного равновесия, когда это равновесие - «по вине» научно-технического прогресса - становится неустойчивым. Технические эксперты обычно предлагают технические решения - как увеличить надежность своих страшных «изделий». Этим занимался и Сахаров вместе со своими коллегами, пока не осознал тупиковость узко-технических решений - слишком тесно главная проблема связана с жизнью человечества.

И он вышел за предписанные рамки. Решение проблемы он увидел в том, что судьба человечества зависит от соблюдения прав отдельной личности. Всеобщие права человека означают открытый мир, в котором только и возможно взаимное узнавание, взаимопонимание, доверие и мирное сосуществование. В мире, разделенном глухими перегородками, само собой возникает взаимное недоверие и страх. Кратко Сахаровскую гуманитарную идею 1968 года можно описать так: справиться с губительной асимметрией большого целого можно, обеспечивая симметрию для его наименьших составляющих. Путь к этой идее, быть может, дался Сахарову легче оттого, что он уже думал о зависимости такого рода, хотя и в совсем другой сфере. Примерно за год до его размышлений о политических асимметриях родилась одна из самых ярких его идей в теоретической физике.

\section{Симметрия и антисимметрия}

Если в политике Сахаров размышлял о том, как обеспечить человечеству более симметричную жизнь, то в физике - наоборот - он пытался понять, почему столь несимметрична Вселенная, управляемая симметричными законами. В обоих случаях он связывал явления самых малых и самых больших масштабов. В социальной жизни - глобальный мир и свободу отдельной личности, а в физике - свойства Вселенной и поведение микрочастиц.

В 20-м веке физики открыли, что элементарные частицы бывают абсолютно тождественными и потому взаимозаменимыми, но бывают и абсолютно противоположными. Настолько противоположными, что при встрече взаимно уничтожаются, только вспышкой сообщая о своей совместной гибели. Такие противоположные частицы назвали античастицами. Первую античастицу теоретически предска- 
зали и экспериментально открыли еще в начале 30-х годов. Это была антикопия электрона - антиэлектрон, за которым закрепилось название «позитрон». Потом экспериментаторы нашли антикопии и других элементарных частиц.

Асимметрия Вселенной, над которой Сахаров задумался в середине 60-х годов, состояла в том, что античастиц во Вселенной очень уж мало - по сравнению с частицами. И слава Богу за такую асимметрию - иначе каждый второй метеорит состоял бы из антивещества. А такой антиметеорит, даже если бы в нем был всего один грамм, соприкоснувшись с веществом Земли, произвел бы взрыв мощности атомной бомбы. Но эту волю Божью физики не понимали - самоочевидным казалось, что всякая частица и ее античастица созданы равными в своих правах. А значит, казалось бы, вещество и антивещество должны быть равно представлены во Вселенной. Астрофизики стали искать признаки антивещества в космосе. Писатели-фантасты устраивали драматические встречи земного космического корабля с неземным и - вполне возможно! - состоящим из антивещества.

Сахаров, однако, со всей серьезностью отнесся к наблюдаемой асимметрии и приписал ее Вселенной в целом, а не просто космическому окружению Земли. Тогда надлежало понять, как симметрия микрочастиц может совмещаться с асимметрией Вселенной. К тому времени, впрочем, симметрия микромира стала уже не столь простой, как правое и левое крылья бабочки, зеркально симметричные (рис.4). В 1956 году произошло знаменательное событие - экспериментаторы обнаружили, что в мире элементарных частиц нет паритета (Parity) правого и левого, или $P$-симметрии. Это знамение те-

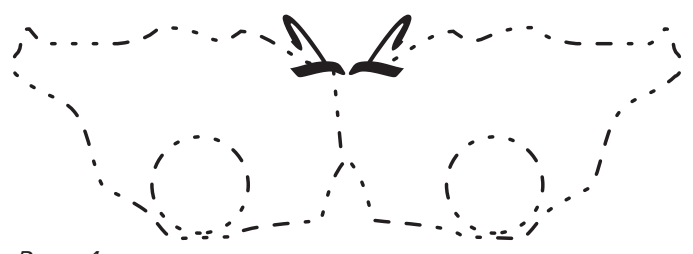

Рис. 4

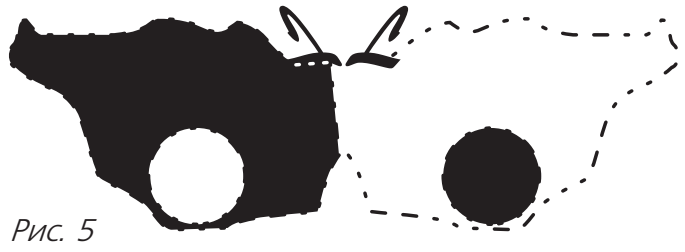

оретики поняли как указание на то, что бабочка микромира выглядит, скорее, так, как на рисунке 5. Иными словами, бабочка не изменится, если одновременно с перестановкой правого и левого поменять местами черный и белый цвета - частицы поменять местами с античастицами и, соответственно, каждый заряд (Charge) заменить на противоположный ему. Это СР-симметрия. Но и она оказалась не последним словом науки. В 1964 году экспериментаторы обнаружили первое не $C P$-симметричное явление.

Что на это могли сказать теоретики? Например, то, что и в обыденной жизни нередко путают правое и левое и превращают белое в черное. Физики-теоретики умеют гораздо более хитрое - изменять направление времени на противоположное. Показывая фильм в обратном направлении, можно зубную пасту, выдавленную из тюбика, вернуть на экране вспять. В реальной жизни никто такого не видел, и физики называют такой процесс асимметричным во времени, или $T$ асимметричным. Что касается элементарных частиц, то физики долгое время считали, что в микромире все явления $T$ симметричны, как в бильярде: сняв на видео соударение шаров и пустив пленку в обратном направлении, ничего странного на экране не заметишь. После крушения $P$-симметрии физики стали всматриваться в другие симметрии. Им не нужна была кнопка обратной перемотки, чтобы задать вопрос о $T$-симметрии в микромире, им хватало ручки и бумаги. В результате они установили самый общий закон симметрии микромира - $C P T$-закон. Чтобы превратить одно крыло СPT-бабочки в другое, надо поменять местами правое и левое, частицу и ее античастицу (черное и белое), прошлое и будущее (перевернуть время $T$ ) (рис.6). 


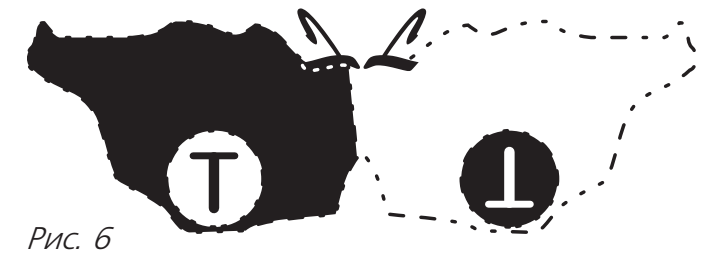

И Сахаров придумал, как такой тройной симметрией микромира объяснить асимметрию Вселенной. Астрономы давно уже обнаружили, что Вселенная несимметрична во времени. Она расширяется - составляющие ее галактики удаляются друг от друга. Сегодня Вселенная шире, чем вчера. А поза-поза-поза...вчеpa? Запустим космологический фильм вспять. Расширение Вселенной теперь выглядит сжатием, галактики приближаются друг к другу, сливаются. При этом сближаются и сами элементарные частицы. Вселенная начинает чувствовать законы микромира.

Именно в ту эпоху, называемую Большим взрывом, асимметрия Вселенной по идее Сахарова - складывалась в процессах, бурлящих тогда в каждой микроточке космического пространства, $T$-асимметрия позволила породить наблюдаемую сейчас $C$-асимметрию - разное содержание частиц и античастиц. Помимо того крылышка вселенской бабочки, которое видно астрономам, физик-теоретик Сахаров увидел мысленно и другое крылышко, раскрывшееся до Большого взрыва (рис.7). Сама эта бабочка CPT-симметрична, но увидеть ее целиком не дает

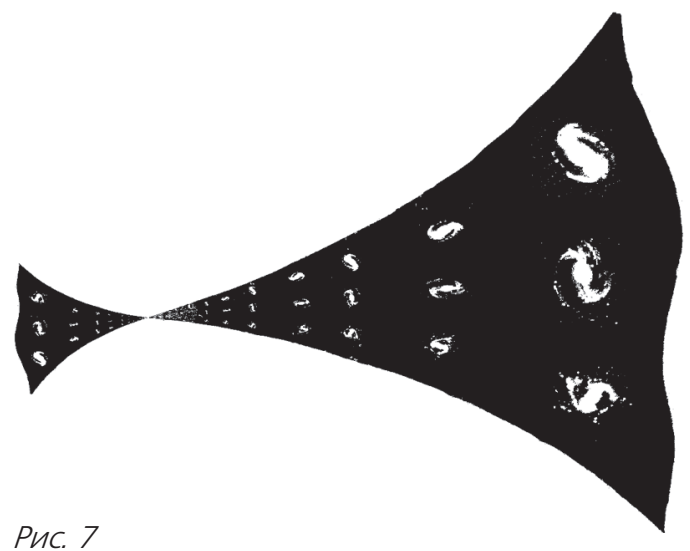

краткость человеческой жизни по сравнению с возрастом Вселенной.

\section{$* * *$}

Удивительно, как много может человек успеть за свою короткую жизнь: научиться писать правой и левой рукой одновременно, разглядеть симметрию асимметричного мира природы и сделать симметричнее мир человека. Примерно так я завершил рассказ об Андрее Сахарове для американских семиклассников. И не был уверен, что они поняли мой рассказ. Поэтому обрадовался, получив из школы пачку благодарственных писем. Одно из них доставило мне особое удовольствие. Автор по-американски сдержанно, но энергично поблагодарил меня за рассказ и выразил надежду, что моя будущая книга о Сахарове станет бестселлером. И подписался:

\section{walle Mass 22oMsilliw Willie Moss ssoM eilliW}

Не сразу я заметил, что он подписался иначе, чем Сахаров, хотя и зеркальносимметрично. Право-лево-рукий Сахаров писал двумя руками от центра к краям $<==>$, а праворукий Вилли, имитируя двурукость, написал $=><=$. Замечательно, что и симметрии и люди бывают такими разными. И что многие загадки Вселенной ждут еще своих разгадок. Для тех, кто хочет ими заняться, Андрей $\mathrm{Ca}-$ харов оставил совет:

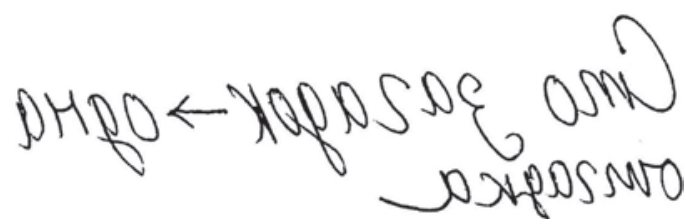

